\title{
TITLE:
}

\section{Factors supporting long-term culture of bovine male germ cells.}

\section{AUTHOR(S):}

Sahare, Mahesh; Kim, Sung-Min; Otomo, Ayagi;

Komatsu, Kana; Minami, Naojiro; Yamada, Masayasu; Imai, Hiroshi

\section{CITATION:}

Sahare, Mahesh ...[et al]. Factors supporting long-term culture of bovine male germ cells.. Reproduction, fertility, and development 2015

\section{ISSUE DATE:}

2015-07-16

URL:

http://hdl.handle.net/2433/202607

\section{RIGHT:}

This is pre-publication version of the article published in final version at http://dx.doi.org/10.1071/RD15003.; この論文は出版社版でありません。引用の際には出 版社版をご確認ご利用ください。; This is not the published version. Please cite only the published version. 
Tittle: Factors supporting a long-term culture of bovine male germ cells

Short Title: Long-term culture of bovine male germ cells

Authors: Mahesh Sahare ${ }^{\mathrm{A}}$, Sung-Min $\mathrm{Kim}^{\mathrm{A}}{ }^{\mathrm{B}}$, Ayagi Otomo ${ }^{\mathrm{A}}$, Kana Komatsu ${ }^{\mathrm{A}}$, Naojiro Minami ${ }^{\mathrm{A}}$, Masayasu Yamada ${ }^{\mathrm{A}}$, Hiroshi Imai ${ }^{\mathrm{A}, \mathrm{C}}$

Addresses: ${ }^{A}$ Laboratory of Reproductive Biology, Graduate School of Agriculture, Kyoto University, Kyoto 606-8502, Japan

${ }^{B}$ Institute of Biogenesis Research, John A. Burns School of Medicine, University of Hawaii, Honolulu, HI 96813, USA

\section{${ }^{\mathrm{C}}$ Correspondence and reprint requests:}

Dr. Hiroshi Imai,

Laboratory of Reproductive Biology,

Graduate School of Agriculture,

Kyoto University, Kyoto 606-8502, Japan

Tel: 15 81-75-753-6058, Fax: 81-75-753-6329,

E-mail: imai@kais.kyoto-u.ac.jp 


\begin{abstract}
Spermatogonial stem cells (SSCs) are unipotent in nature, but acquire pluripotency under the appropriate culture conditions in mice. Although culture systems are available for rodent and human germ cell lines, no proven culture system is yet available for livestock species. Here, we examined growth factors, matrix substrates and serum-free supplements to develop a defined system for culturing primitive germ cells (gonocytes) from neonatal bovine testis. Poly-L-lysine was a suitable substrate for selective inhibition of the growth of somatic cells and made it possible to maintain a higher gonocyte/somatic cell ratio than those maintained with gelatin, collagen or Dolichos biflorus agglutinin (DBA) substrates. Among the serum-free supplements tested in our culture medium, knockout serum replacement (KSR) supported the proliferation and survival of gonocytes better than the supplements B-27 and StemPro-SFM after sequential passages of colonies. Under our optimized culture conditions consisting of $15 \% \mathrm{KSR}$-supplement on poly-L-lysine-coated dishes, the stem cell and germ cell potentials of the cultured gonocytes were maintained with normal karyotype for more than 2 months (over 13 passages). The proposed culture system, which can maintain a population of proliferating bovine germ stem cells, could be useful for studying SSCs biology and germline modifications in livestock animals.
\end{abstract}

Key words: GDNF, gonocytes, self-renewal, KSR, long-term culture, testis

\title{
Introduction
}

SSCs are unique adult germ cells found in the testis, which undergo self-renewal and differentiation to produce spermatozoa throughout a life and transmit genetic information across generations (De Rooij et al. 1999). These cells postnatally ascend from gonocytes (primitive germ cells), which reside mostly in the center of the seminiferous tubules and remain quiescent (Vergouwen et al. 1993). Gonocytes resume proliferation, migrate to the basement membrane and then transformed into SSCs after arriving at a stem cell niche. The niche is a specialized microenvironment in the seminiferous tubules, and provides extrinsic stimuli that promote the self-renewal of SSCs or their differentiation into meiotic germ cells (Oatley et al. 2003). Pluripotent and multipotent stem cell lines has been developed from unipotent SSCs in mice (Kanatsu-Shinohara et al. 2007; Seandel et al. 2007) and humans (Conrad et al. 2007). The generation of these autologous pluripotent cell lines from SSCs before the initiation of cancer treatment and subsequent autologous transplantation after cancer treatment could be a means of preserving the fertility of male cancer patients (Struijk et al. 2013). 
The limited number of SSCs in the testis hampers their studies of the biological characteristics (Meistrich et al. 1993). One approach to solve this problem is to develop culture conditions that support the self-renewal of SSCs and that maintain their pluripotency in culture. Glial-cell-line-derived neurotrophic factor (GDNF) was identified, as a factor that is required for SSCs self-renewal in vivo (Meng et al. 2000). Subsequently, a short-term culture system supplemented with GDNF has been developed by Nagano et al. (2003). These cells complete spermatogenesis after transplantaion into the testis of immunodeficient mice. Longer-term culture of SSCs was achieved by adding other growth factors and hormones in addition to GDNF (Kanatsu-Shinohara et al. 2003). However, the growth factor requirement for proliferation of germ cells is strain specific; in mice, strains C57BL/6 and 129/Sv require FGF and GDNF (Kubota et al. 2004), while strain DBA requires FGF, GDNF and EGF (Kanatsu-Shinohara et al. 2005). The well defined culture systems and germ cell lines have been established in rat (Hamra et al. 2005; Ryu et al. 2005), hamster (Kanatsu-Shinohara et al. 2008) and rabbit (Kubota et al. 2011) by using species-specific culture components.

In livestock species, long-term culture systems for germ cells could reduce the time and money needed to produce transgenic animals and to preserve endangered species, and could be an alternative for pronuclear microinjection and somatic cell cloning (Dobrinski et al. 2006). Although several attempts have been made to develop a culture system for bovine SSCs, most of these studies achieved only short-term cultures of SSCs from pre-pubertal testis (Izadyar et al. 2002; Izadyar et al. 2003; Oatley et al. 2004; Aponte et al. 2005; Aponte et al. 2006) and neonatal testis (Fujihara et al. 2011). In these studies, serum was used as an important component in the culture medium for survival and self-renewal of culture cells. Some undefined factors in serum induce cell differentiation, while others have detrimental effects on ES cells and germ cell survival in culture (Li et al. 2998; Kubota et al. 2004). To overcome this problem, serum-free culture systems have been developed for long-term cultures of SSCs in mice (Kubota et al. 2004; Kanatsu-Shinohara et al. 2011) and rat (Ryu et al. 2005). However, no proven long-term culture systems for livestock species were established. Here, we describe a long term culture system that supports continuous proliferation of bovine gonocytes in vitro.

\section{Materials and methods}

\section{Collection of testes and isolation of gonocytes}


Testes were collected from 0 to 10-day-old Holstein bull calves in Dulbecco's modified Eagle's medium and Ham's F12 (DMEM/F12; GIBCOBRL Invitrogen, Carlsbad, CA, USA) supplemented with $15 \mathrm{mM}$ HEPES (Wako Pure Chemical, Tokyo, Japan) and were transported to the laboratory on ice within 24 hours.

Gonocytes were isolated by a three-step enzymatic digestion method as described previously (Kim et al. 2014) with minor modifications. Briefly, the testes were encapsulated, minced and digested with collagenase Type IV $(1 \mathrm{mg} / \mathrm{ml}$; Sigma-Aldrich, St. Louis, MO, USA) at $37{ }^{\circ} \mathrm{C}$ for 45 min with constant agitation. After three washes, tissue fragments of the seminiferous tubules were incubated with collagenase Type IV and hyaluronidase (Sigma-Aldrich), each at a final concentration of $1 \mathrm{mg} / \mathrm{ml}$. The cell suspension was further incubated with a mixture of $0.25 \%$ trypsin (Nacalai-Tesque, Kyoto, Japan) and DNase I (7 mg/ml; Sigma-Aldrich) for $10 \mathrm{~min}$. After centrifugation, the pellet was suspended in DMEM/F12 medium containing 10\% FBS to stop enzymatic activity of trypsin. The cell suspension was filtered through $40 \mu \mathrm{m}$ nylon mesh (Kyoshin Rikou, Tokyo, Japan) and suspended in DMEM/F12 medium containing $5 \%$ FBS.

\section{Enrichment of gonocytes for culture}

The cell suspension was subjected to Percoll density gradient centrifugation. Cells from the fraction between 35 to $45 \%$ Percoll were separated and plated on $0.2 \%$ gelatin-coated dishes (Sigma-Aldrich) for 6 hours in DMEM/F12 medium containing $5 \%$ FBS. The supernatant containing gonocytes were collected and utilized for further experiments.

The culture medium (the basic medium) for gonocytes consisted of DMEM/F12 supplemented with $10 \mu \mathrm{g} / \mathrm{ml}$ apo-transferin (Sigma-Aldrich), $10 \mu \mathrm{g} / \mathrm{ml}$ insulin (Sigma-Aldrich), $110 \mu \mathrm{g} / \mathrm{ml}$ sodium pyruvate (Sigma-Aldrich), 0.015\% sodium DL-lactate (Sigma-Aldrich), NEAA (non-essential amino acid solution, GIBCOBRL Invitrogen, Carlsbad, CA, USA), $100 \mu \mathrm{M} \beta$-mercaptoethanol (Wako Pure Chemical, Tokyo, Japan), $100 \mu \mathrm{g} / \mathrm{ml}$ Penicillin (Sigma-Aldrich), and $50 \mu \mathrm{g} / \mathrm{ml}$ Streptomycin (Sigma-Aldrich), $40 \mu \mathrm{g} / \mathrm{ml}$ Gentamycin (Sigma-Aldrich) with 1\% FBS. The growth factors used in this study were GDNF (40 ng/ml, R\&D, Minneapolis, MN, USA), bFGF (10 ng/ $\mu 1$, Upstate, Temecula, CA, USA) and EGF (20 ng/ $\mu 1$, JRH Bioscience, Lenexa, KS, USA).

The serum-free supplement KSR (GIBCOBRL, Invitrogen, Carlsbad, CA, USA), B-27 (50X) (GIBCOBRL, Invitrogen, Carlsbad CA, USA) or StemPro-SFM (100X) (GIBCOBRL, Invitrogen, Carlsbad, CA, USA) was used as a reduced serum substitution 
for a germ cell culture. The medium is supplemented with the final concentration of KSR (15\%), B-27 (1X) and StemPro-SFM (1X). Cells were seeded in various media in 6-well dishes coated with different ECM-substrates (Iwaki, Tokyo, Japan) at a density of $5 \times 10^{5}$ per well at $37^{\circ} \mathrm{C}$ in $5 \% \mathrm{CO}_{2}$ in air. For a long-term culture, cells were plated on poly-L-lysine pre-coated dishes. Cells were enzymatically passaged every 4 to 6 days at 1:2 to 1:4 dilution of cell concentration. The culture dishes were washed with phosphate buffered saline (PBS) and incubated in $0.025 \%$ trypsin and $0.04 \%$ EDTA solution for 7 min followed by vigorous pipetting for $3 \mathrm{~min}$. The trypsin treatment was inhibited by the medium supplemented with 10\% FBS. Dissociated cells were washed with PBS and counted using a hemocytometer and were plated onto new dishes. Cell smears were prepared for the estimation of germ cell numbers at every passages. Briefly, dissociated cells $\left(1 \times 10^{5}\right)$ were fixed with $4 \%$ paraformaldehyde for $10 \mathrm{~min}$. After washing, $10 \mu \mathrm{l}$ of cell suspension was put on poly-L-lysine coated glass slide, air-dried and keep at $4{ }^{0} \mathrm{C}$ until the use for immunocytochemistry. The colonies were counted manually with an inverted microscope (Nikon, DIAPHOT-300, Japan).

\section{Preparation of ECM-coated culture dishes}

Culture dishes were coated with four different ECM molecules: $0.2 \%$ gelatin (Sigma-Aldrich), 0.001\% poly-L-lysine (P2658, Sigma-Aldrich), $20 \mathrm{ug} / \mathrm{ml}$ collagen (Sigma-Aldrich) or $30 \mathrm{ug} / \mathrm{ml}$ DBA (Victor Laboratories, Burlingame, CA, USA) for 1 $\mathrm{hr}$ at $37^{\circ} \mathrm{C}$. DBA-coated dishes support cell adhesion and induce proliferation of bovine gonocytes (Kim et al. 2014). Culture dishes were washed once with PBS and further utilized for culture experiments.

\section{Immunocytochemistry}

The purity of gonocytes was estimated by using anti-UCHL1 (1:200; Biomol, Exeter, Exeter, UK) and anti-VIMENTIN (1:100; Sigma-Aldrich). The estimation of gonocytes was calculated using DBA-FITC (1:200, Vector Laboratories, Burlingame, CA, USA) staining on cell smear prepared at every passage. DBA and UCHL1 are recognized as a specific marker for the identification of gonocytes and spermatogonial stem cells in cattle (Fujihara et al. 2011). Colonies were double stained with fluorescein isothiocyanate (FITC)-conjugated DBA-Rhodamine (1:100; Vector Laboratories, Burlingame, CA, USA) and stem cell-specific markers anti-OCT3/4 (1:200; Santa Cruz Biotechnology, Santa Cruz, CA, USA), anti-NANOG (1:200; Chemicon International, Temecula, CA, USA) and anti-E-CADHERIN (1:200; Santa Cruz Biotechnology) antibodies, and also germ cell-specific markers anti-DDX4 (1:300; Chemicon International) and anti-GFR $\alpha-1$ (Santa Cruz Biotechnology). The procedure was 
performed as described previously (Fujihara et al. 2011). Briefly, cells were fixed with $4 \%$ paraformaldehyde for $10 \mathrm{~min}$ and incubated with $10 \%$ goat serum in TBS (Tris-buffered saline) containing $0.1 \%$ Triton $\mathrm{X}-100$ for $1 \mathrm{hr}$ at $37{ }^{0} \mathrm{C}$. The samples were washed and then incubated with primary antibodies at the optimal concentrations overnight at $4^{0} \mathrm{C}$. Samples were then washed and incubated with anti-mouse or anti-rabbit IgG antibodies conjugated with FITC (1:200; DAKO A/S, Glostrup, Denmark) as secondary antibodies along with DBA-Rhodamine (1:100). Samples were counterstained with $1 \mu \mathrm{g} / \mathrm{ml}$ Hoechst 33342 (Sigma-Aldrich) for $5 \mathrm{~min}$ and mounted with $50 \%$ glycerol. For DBA staining on cell smears, the procedure was performed as above with a slight modification. After blocking $10 \%$ goat serum in TBS, samples were incubated with DBA-FITC $(1: 200)$ for $2 \mathrm{hr}$ in dark. Samples were then washed thrice, counterstained with Hoechst 33342 for 5 min, and mounted with $50 \%$ glycerol. For negative control, primary antibodies were omitted and the sections was incubated with secondary antibodies mouse normal IgG (1:200 dilution, Santa Cruz Biotchnology) or rabbit normal IgG (1:200 dilution, Santa Cruze, USA). Photographs were taken with the inverted fluorescent microscope, Eclipse TE2000-U (Olympus BX50, Tokyo, Japan). Cell proliferation was measured by double staining with Ki67 antibody (1:100; DAKO $\mathrm{A} / \mathrm{S}$,) along with DBA-Rhodamine (1:100). The samples were processed as described above.

\section{In-vitro differentiation assay}

Cultured gonocytes were harvested by trypsinization and cultivated in Iscove's modified Dulbecco's medium (IMDM, Gibco) supplemented with 15\% FBS, 2 mM L-glutamine, 1x NEAA and $100 \mu \mathrm{M} \beta$-mercaptoethanol (Wako) as described for the standard procedure for cell differentiation of mouse embryonic stem cells (ESC) (Guan et al. 1999). Briefly, $1 \times 10^{3}$ cells in 30- $\mu$ l differentiation media were placed in one well of an ultra low attachment 96 well dish (Sumitomo Bakelite, Akita, Japan) and incubated for 5 days. Embryoid bodies were collected, trypsinized into single cells and plated on gelatin-coated dishes upto 5 days for cell differentiation analysis.

Germ cell differentiation was characterized by using primary antibodies to the following proteins: glial fibrillary acid protein (GFAP, 1:100, DAKO A/S), $\alpha$-smooth muscle (ASM, 1:000, Thermo Scientific, USA), and $\alpha$-fectoprotein (AFP1:100, R\&D, Minneapolis, MN, USA). Cell smears were immunostained and photographed as described above.

\section{Karyotype analysis}

Cultured cells were incubated overnight with $0.1 \mathrm{ug} / \mathrm{ml}$ Karyomax colcemid solution 
(Gibco). Cells were harvested as single cell suspensions and metaphase spreads were prepared as previously described (Garcia-Gonzalo et al. 2008). The slides were stained with VECTA SHIELD mounting medium with DAPI (Vector Laboratories). Twenty metaphase spreads were examined on two established cell lines. The number of chromosomes was calculated manually.

\section{$R N A$ isolation and reverse transcriptase-polymerase chain reaction ( $R T-P C R)$}

Total RNAs were isolated with Trizol reagent (Invitrogen) according to the manufacturer's protocol. The DNase activity was inhibited by treating $2 \mathrm{U}$ of RNase-free DNase (Roche, Mannheim, Germany). Complementary DNA was synthesized from 1 $\mu \mathrm{g}$ total RNA using ReverTra Ace (MMLV reverse transcriptase RNaseH; Toyobo, Osaka, Japan). To rule out genomic DNA contamination, the PCR reactions were performed for samples without template DNA. The PCR amplification was performed using $1 \mu \mathrm{L}$ cDNA per $20 \mu \mathrm{L}$ PCR reaction mixture containing $2 \mathrm{mM} \mathrm{MgCl}, 0.25 \mathrm{mM}$ dNTPs, $1 \times$ PCR buffer, 5 pmol of each primer and 1U Taq DNA polymerase (ExTaq; TaKaRa). Nucleotide sequences are obtained from GenBank and primer pairs were designed using Primer 3 programme (http://primer3.sourceforge.net/) are given in Table 1. PCR amplification conditions were carried out as an initial denaturation at $95^{\circ} \mathrm{C}$ for 5 min ( 1 cycle), followed by 29 cycles of the denaturation at $95^{\circ} \mathrm{C}$ for $30 \mathrm{sec}$, annealing at $60^{\circ} \mathrm{C}$ for $30 \mathrm{sec}$, extension at $72^{\circ} \mathrm{C}$ for $45 \mathrm{sec}$, and a final extension at $72^{\circ} \mathrm{C}$ for $5 \mathrm{~min}$. The PCR products were separated by $1.5 \%$ agarose gel electrophoresis and stained with $0.5 \mu \mathrm{gmL}^{-1}$ ethidium bromide. All PCR products were sequenced to confirm their identity.

\section{Statistical analysis}

Differences among experimental groups were tested by ANOVA using GraphPad Prism 4.0 (GraphPad Software, San Diego, CA, USA). Data are presented as the mean \pm SEM $(n=4)$ in each group from three independent experiments. Differences were considered to be significant at $\mathrm{p}<0.05$.

\section{Results}

\section{Enrichment of gonocytes and selection of coating substrates for germ cell culture}

Gonocytes were enriched by positive selection through Percoll centrifugation and negative selection on gelatin-coated culture dishes (Fig. 1A). The overall purity of gonocytes, assessed by the localization of germ cell marker UCHL1 (Fujihara et al. 2011) and somatic cell marker VIMENTIN was approximately $81.00 \pm 2.08 \%(n=4)$ (Fig. 1B). This indicates that the ratio of gonocytes to somatic cells was $4.46 \pm 0.62$. 
To suppress the overgrowth of somatic cells, we tried coating the culture dishes with different substrates. Colonies appeared on gelatin-, collagen- and DBA-coated dishes after 3 days of culture and gradually disappeared by 7 days (Fig. 1C (a, c and d)). Colonies emerged on a poly-L-lysine-coated dish at 4 days and gradually increased in size with a distinct dome-like morphology and limited proliferation of somatic cells (Fig. $1 \mathrm{C}$ (b)). The ratios of gonocytes to somatic cells at day 7 of culture were significantly reduced on the gelatin $(0.62 \pm 0.30)$, collagen $(0.69 \pm 0.28)$ and DBA $(1.08 \pm 0.28)$ coated dishes than they were on day $0(4.46 \pm 0.62)$. The ratio on the poly-L-lysine-coated dish $(3.17 \pm 0.33)$ (Fig. 1D) was several times higher than the ratios on the other coated dishes. Gonocytes to somatic cells ratio is calculated by using DBA staining as germ cell marker shown by (Kim et al, 2014) to count actual germ cell numbers (Fig. 1E).

\section{Effects of different serum-free supplements on germ cell culture}

To optimize culture conditions for survival and self-renewal of bovine gonocytes, we tested different media formulations using poly-L-lysine-coated dishes in short-term culture. Based on the preliminary standardization (data not shown) and published reports (Kanatsu-Shinohara et al. 2011; Oatley et al. 2004 and Aponte et al. 2006), the medium was supplemented with FBS (1\%) and GDNF (40 ng/ul). The addition of growth factors bFGF and EGF to the medium enhanced the proliferation of somatic cells. Therefore, to suppress the overgrowth of somatic cells in culture, bFGF and EGF were excluded from the culture medium in further experiments.

To find suitable serum-free supplements for a long-term culture of bovine gonocytes, we evaluated KSR, B27 and StemPro-SFM supplements in the culture medium. Gonocytes in the medium containing KSR showed 51.34 \pm 10.62 -fold expansion as compared to control (no serum-free supplement, 20.18 \pm 1.95 -fold), B-27 (29.50 \pm 1.19 -fold), StemPro-SFM (24 \pm 5.3 -fold) during 17 days of cultures (passage 3 ) (Fig. 2).

\section{Long-term culture of gonocytes in KSR-supplemented medium}

KSR-supplemented medium, had given promising results in our preliminary culture, was utilized for long-term culture of gonocytes. The cultured cells were passaged enzymatically using trypsin-EDTA into small clumps every 4 to 5 days. Distinct embryonic stem (ES) cell-like colonies were appeared at every passage with expansion of gonocytes. The morphologies of colonies of representative passages are shown in Fig 
3. The number of gonocytes increased 140 fold in 67 days (Fig 4).

\section{Phenotypic characterization of gonocytes in a long-term culture}

Distinct ES cell-like colonies stably appeared at successive passages during the long-term culture. As shown by RT-PCR gene expression profiles, cells from the colonies expressed pluripotent markers OCT3/4 and $c-M Y C$ and germ cell marker UCHL1 at passages P0, P5, P10 and P13 (Fig 5). At passage 10 (corresponding to more than 2 months of culture), 75 to $80 \%$ of the cells from twenty metaphase spreads that were counted from each of two cell lines had a normal karyotype (60 chromosomes) (Fig 6).

\section{Molecular characterization of gonocytes derived cell colonies in a long-term culture}

At passage 10, the colonies were positive for DBA with OCT3/4, NANOG, E-CAD and also positive for proliferation marker Ki-67 (Fig 7).

\section{Differentiation potential of gonocytes}

Cultured gonocytes were used for embryoid body formation. Five days after the start of passage 10, the cells formed embryoid bodies (Fig 8A). The cells were positive for the expressions of $\alpha$-fectoprotein (AFP), an endoderm lineage protein, $\alpha$-smooth muscle (ASM), a mesoderm lineage protein, and glial fibrillary acid protein (GFAP), an ectoderm lineage protein, as compared to control (Fig 8B).

\section{Discussion}

The growth of male germ cells in culture can be adversely affected by the presence of contaminating somatic cells from the testes. Such cells can be minimized by applying a suitable coating to culture dish (Kubota et al. 2004). In our study, poly-L-lysine-coated dishes selectively inhibited the proliferation of testicular somatic cells and supported the proliferation of gonocytes in culture, while the mechanism by which it supported proliferation was unknown. One of the mechanism by which poly-L-lysine promotes attachment and growth of cells is due to its highly positive charged nature (Mckeehan et al. 1976). In addition, poly-L-lysine is a key component in a defined culture medium for mouse ES cells (Harb et al. 2008). In short-term culture of bovine germ cells from 3.5-month-old pre-pubertal testis, DBA-coated dishes were observed to be a better support for the binding and survival of cells than gelatin-, poly-L-lysine- and laminin-coated dishes (Kim et al. 2014). This indicates that there are age-specific differences in requirements of DBA- and poly-L-lysine-coated dishes for self-renewal and proliferation of bovine neonatal and pre-pubertal germ cells. Similarly, in mice, pre-pubertal (SSCs) and germ cells (gonocytes) were found to have different growth 
requirements (Creemers et al. 2002). To propagate and maintain the pluripotency of mouse ES cells, extrinsic cell differentiation stimuli need to be suppressed and neutralized (Ying et al. 2003). The differentiation of mouse SSCs was directly influenced by environmental factors, i.e. growth factors and serum (Kanatsu-Shinohara et al. 2011). Growth factors, such as GDNF, bFGF and EGF, are required for the long-term culture of germ cells in mice and rat (Kubota et al. 2004 and Wu et al. 2009). In our studies, the addition of bFGF and EGF in cattle gonocyte culture resulted in the overgrowth of somatic cells in the short-term culture. Culture medium supplemented with GDNF, bFGF and EGF did not support the appearance of germ cell colonies during a long-term culture in cattle (Aponte et al. 2008). These results indicate that mice and cattle germ cells need different factors for cell growth. Similarly, our previous findings reveal that MAPK signaling plays the crucial role in maintaining the self-renewal and colony formation of bovine gonocytes in culture while cultured mouse germ cells require the crosstalk between MAPK and PI3K signaling pathways for self-renewal (Sahare et al. 2014). These different signaling pathways are activated under the influence of different growth factors. The addition of serum to the culture medium reduces germ cell survival, and a reduced concentration of serum is essential for the maintenance of stem-cell activity (Kanatsu-Shinohara et al. 2011). Testicular cells from neonatal bovine testis do not grow well in medium supplemented with $10 \%$ FBS (Fujihara et al. 2011), indicating that higher concentrations of serum have adverse effects on the growth of bovine germ cells.

Serum-free supplement KSR, has been shown to prolong the culture of human ES cells (Amit et al. 2011), mice embryonic germ cells (EGCs) (Horii et al. 2003) and pig EGCs (Petkov et al. 2008). StemPro-SFM is a standard supplement for germ cell culture in mice (Kanatsu-Shinohara et al. 2003), while B27 supplement is required for germ cell culture in rat (Wu et al. 2009). In our experiment, KSR-supplement medium is more effective than that of B-27 or StemPro-SFM supplement for the long-term culture of bovine neonatal germ cells. Current studies advocate that Albumax (a lipid-rich BSA) present in KSR-supplement stimulate self-renewal of human ES cells (Garcia-Gonzalo et al. 2008). BSA and lipid-rich BSA are required for the self-renewal of SSCs in culture through a lipid-mediated signaling pathway (Kubota et al. 2004; Kanatsu-Shinohara et al. 2011). The lipid-rich BSA in KSR-supplement, which is not in B27 (Garcia-Gonzalo et al. 2008) or StemPro-SFM (Kanatsu-Shinohara et al. 2003), may contribute to the long-term culture of bovine gonocytes. Further studies are needed to elucidate the mechanism by which lipid-rich BSA mediates self-renewal of 
gonocytes.

By using KSR and poly-L-lysine-coated culture dishes, we could propagate gonocytes for over 2 months with a normal karyotype. We established three cell lines from three different testis isolations. The expansion of gonocytes after enzymatic passages suggests that this culture condition is suitable for the minimizing the unfavorable effects that are caused by the enzyme treatment.

The expression of pluripotent genes OCT3/4 and $c-M Y C$ in colonies indicated that cultured gonocytes had stem-cell characteristics while $U C H L I$ expression indicated that they had germ cell potential throughout the term of culture (Fig. 5). Immunocytochemical analysis also revealed stemcell (OCT3/4, NAOAG and E-CAD expressions) and germ cell characteristics (DDX4 and GFR $\alpha-1)$ in the long-term culture. In our studies, cell lines that derived from the cultured gonocytes formed embryoid bodies and differentiated into all three germ layers. However, subcutaneously injecting these cells into the backs of immunodeficient mice did not form teratomas. The bovine genital ridge including PGC can develop into tumors under the kidney capsule and the pluripotent capacity of PGC provides a possibility for a generation of bovine stem cell line (Choi and Anderson 1998). Cultured porcine gonocytes can produce teratoma upon subcutaneous injection in the back of nude mice (Goel et al. 2009). However, teratoma formation can be influenced by various factors like the origin of undifferentiated stem cells, genetic background of recipient mouse strain, the delivery site of transplantation and injected cell numbers (Mohseni et al.2014).

The culture condition for the propagation of undifferentiated bovine gonocytes was improved by using poly-L-lysine-coated dishes in the medium containing KSR. Further investigation is needed in order to characterize species-specific signaling pathways regulated by cytokines and their association with self-renewal gene cascade for improvement of culture conditions. Our culture condition will pave the way towards the establishment of germ stem cell lines in livestock species as well as provide the model for application of this research on conservation of endangered species.

\section{Acknowledgements}

The authors thank Drs. K. Konishi and Y. Hashiyada (National Livestock Breeding Center) and Dr. Y. Hoshino (Gifu Prefectural Livestock Research Institute) for providing bovine testis samples. This study was supported by a grant from the Japan Society for the Promotion of Science (JSPS) to MS and a grant from the Ministry of Education, Culture, Sports, Science and Technology of Japan (MEXT) to HI. 


\section{References}

Amit, M., Shariki, C., Margulets, V., and Itskovitz-Eldor, J. (2004). Feeder layer- and serum-free culture of human embryonic stem cells. Biol. Reprod. 70, 837-845. doi: 10.1095/biolreprod.103.021147

Aponte, P.M., Soda, T., Kant, H. J. G., and Van, De. (2006). Basic features of bovine spermatogonial culture and effects of glial cell line-derived neurotrophic factor. Theriogenology

65, $1828-1847$.

doi: http://dx.doi.org/10.1016/j.theriogenology.2005.10.020

Aponte, P. M., Soda, T., Teerds, K. J., Mizrak, S. C., van de Kant, H. J. G., and de Rooij, D. G. (2008). Propagation of bovine spermatogonial stem cells in vitro. Reproduction 136, 543-557. doi: 10.1530/REP-07-0419

Choi, S. J., and Anderson, G. B. (1998). Development of tumors from bovine primordial germ cells transplanted to athymic mice. Anim. Reprod. Sci. 52, 17-25.

Conrad, S., Renninger, M., Hennenlotter, J., Wiesne,r T., Just, L., Bonin, M., Aicher, W., Bühring, H. J., Mattheus, U, Mack, A., Wagner, H. J., Minger, S., Matzkies. M., Reppel, M., Hescheler, J., Sievert, K. D., Stenzl, A., and Skutella, T. (2008). Generation of pluripotent stem cells from adult human testis. Nature 456, 344-349. doi: 10.1038/nature07404

Creemers, L. B., Den Ouden, K., Van, Pelt, A. M., and de Rooij, D. G. (2002) Maintenance of adult mouse type A spermatogonia in vitro: influence of serum and growth factors and comparison with prepubertal spermatogonial cell culture. Reproduction 124, 791-799. doi: 10.1530/rep.0.1240791

De Rooij, D. G., Okabe, M., and Nishimune, Y. (1999). Arrest of spermatogonialdifferentiation in jsd/jsd, $\mathrm{S} 117 \mathrm{H} / \mathrm{S} 117 \mathrm{H}$, and cryptorchid mice. Biol. Reprod. 61, 842-847. doi: 10.1095/biolreprod61.3.842

Dobrinski, I. (2006). Transplantation of germ cells and testis tissue for the study of mamalian spermatogenesis. Anim. Reprod. 3, 135-1345. 
Fujihara, M., Kim, S,M., Minami, N., Yamada, M., and Imai, H. (2011). Characterization and in vitro culture of male germ cells from developing bovine testis. J. Reprod. Dev. 57, 355-364. doi:http://dx.doi.org/10.1262/jrd.10-185M

Garcia-Gonzalo, F. R., and Izpisúa-Belmonte, J. C. (2008). Albumin-associated lipids regulate human embryonic stem cell self-renewal. PLoS One. 3, e1384. doi: 10.1371/journal.pone.0001384.

Guan, K., Rohwedel, J., and Wobus, A. M. (1999). Embryonic stem cell differentiation models: cardiogenesis, myogenesis, neurogenesis, epithelial and vascular smooth muscle cell differentiation in vitro. Cytotechnology 30, 211-226. doi: 10.1023/A:1008041420166.

Hamra, F. K., Chapman, K. M., Nguyen, D. M., Williams-stephens, A. A., Hammer, R. E., and Garbers, D. L. (2005). Self renewal, expansion, and transfection of rat spermatogonial stem cells in culture. Proc. Natl. Acad. Sci. USA. 102, 17430-17435. doi: 10.1073/pnas.0508780102

Harb, N., Archer, T. K., and Sato, N. (2008). The Rho-Rock-Myosin signaling axis determines cell-cell integrity of self-renewing pluripotent stem cells. PLoS One. 3, e3001. doi: 10.1371/journal.pone.0003001.

Horii, T., Nagao, Y., Tokunaga. T., and Imai, H. (2003). Serum-free culture of murine primordial germ cells and embryonic germ cells. Theriogenology 59, 1257-1264. doi: http://dx.doi.org/10.1016/S0093-691X(02)01166-4

Izadyar F, Den Ouden K, Stout T a E, Stout J, Coret J, Lankveld, D. P., Spoormakers, T. J., Colenbrander, B., Oldenbroek, J. K., Van der Ploeg, K. D., Woelders, H., Kal, H. B., and De Rooij, D. G. (2003). Autologous and homologous transplantation of bovine spermatogonial stem cells. Reproduction 126, 765-774. doi: 10.1530/rep.0.1260765

Izadyar, F., Spierenberg, G. T., Creemers, L. B., den Ouden, K., and de Rooij, D. G. (2002). Isolation and purification of type A spermatogonia from the bovine testis. Reproduction 124, 85-94. doi: 10.1530/rep.0.1240085 
Kanatsu-Shinohara, M., Inoue, K., Lee, J., Yoshimoto, M., Ogonuki, N., Miki, H., Baba, S., Kato, T., Kazuki, Y., Toyokuni, S., Toyoshima, M., Niwa, O., Oshimura, M., Heike, T., Nakahata, T., Ishino, F., Ogura, A., and Shinohara, T. (2004). Generation of Pluripotent Stem Cells from Neonatal Mouse Testis. Cell 119, 1001-1012.

Kanatsu-Shinohara, M., Inoue, K., Ogonuki, N., Morimoto, H., Ogura, A., Shinohara, T. (2011). Serum- and feeder-free culture of mouse germline stem cells. Biol. Reprod. 84, 97-105. doi: 10.1095/biolreprod.110.086462.

Kanatsu-Shinohara, M., Miki, H., Inoue, K., Ogonuki, N., Toyokuni, S., Ogura, A., and Shinohara, T. (2005). Long-term culture of mouse male germline stem cells under serum-or feeder-free conditions. Biol. Reprod. 72, 985-991. biolreprod.104.036400v1

Kanatsu-Shinohara, M., Muneto, T., Lee, J., Takenaka, M., Chuma, S., Nakatsuji, N., and Shinohara, T. (2008). Long-term culture of male germline stem cells from hamster testes. Biol. Reprod. 78, 611-617. doi: 10.1095/biolreprod.107.065615

Kanatsu-Shinohara, M., Ogonuki, N., Inoue, K., Miki, H., Ogura, A., Toyokuni, S., and Shinohara, T. (2003). Long-term proliferation in culture and germline transmission of mouse male germline stem cells. Biol. Reprod. 69, 612-616. doi: 10.1095/biolreprod.103.017012

Kim, S. M., Fujihara, M., Sahare, M., Minami, N., Yamada, M., and Imai, H. (2014). Effects of extracellular mas and lectin Dolichos Biflorus Agglutinin on cell adhesion and self-renewal of bovine gonocytes cultured in vitro. Reprod. Fertil. Dev. 26, 268-281. doi: 10.1071/RD12214.

Kubota, H., Avarbock, M. R., and Brinster, R. L. (2004). Growth factors essential for self-renewal and expansion of mouse spermatogonial stem cells. Proc. Natl. Acad. Sci. USA. 101, 16489-16494. doi: 10.1073/pnas.0407063101

Kubota, H., Wu, X., Goodyear, S. M., Avarbock, M. R., and Brinster, R. L. (2011). Glial cell line-derived neurotrophic factor and endothelial cells promote self-renewal of rabbit germ cells with spermatogonial stem cell properties. FASEB J. 25, 2604-2614. doi: 10.1096/fj.10-175802. 
Li, P., Tong, C., Mehrian-Shai, R., Jia, L., Wu, N., Yan, Y., Maxson, R. E., Schulze, E. N., Song, H., Hsieh, C. L., Pera, M. F., and Ying, Q. L. (2008). Germline competent embryonic stem cells derived from rat blastocysts. Cell 135,1299-1310. doi: 10.1016/j.cell.2008.12.006.

Mckeehan, W. L., and Ham, R.G. (1976). Stimulation of clonal growth of normal fibroblasts with substrata coated with basic polymers. J. Cell. Biol. 71, 727-734.

Meistrich, M., and VanBeek, M. (1993). Spermatogonial stem cells. In: Desjardins C, Ewing LL. Editors. The cell and molecular biology of testis. Oxford University Press, New York, 266-295.

Meng, X. (2000). Regulation of Cell Fate Decision of Undifferentiated Spermatogonia by GDNF. Science 287,1489-1493. doi:10.1126/science.287.5457.1489

Mohseni, R., Hamidieh, A. A., Verdi, J., and Shoae-Hassani, A. (2014). Safe transplantation of pluripotent stem cell by preventing teratoma formation. Stem Cell. Res. Ther. 4, 212. doi: 10.4172/2157-7633.1000212

Nagano, M., Ryu, B,Y., Brinster, C. J., Avarbock, M. R., and Brinster, R. L. (2003). Maintenance of mouse male germ line stem cells in vitro. Biol. Repod. 68, 2207-2214. doi: 10.1095/biolreprod.102.014050

Oatley, J. M., and Brinster, R. L. (2008). Regulation of Spermatogonial Stem Cell Self-Renewal in Mammals. Annu. Rev. Cell. Dev. Biol. 24, 263-288. doi: 10.1146/annurev.cellbio.24.110707.175355.

Oatley, J. M., and Brinster, R. L. (2012). The germline stem cell niche unit in mammalian testes. Physiol. Rev. 92, 577-595. doi: 10.1152/physrev.00025.2011

Oatley, J. M., Reeves, J. J., and McLean, D. J. (2004). Biological activity of cryopreserved bovine spermatogonial stem cells during in vitro culture. Biol. Reprod. 71, 942-947. doi: 10.1095/biolreprod.104.028894

Petkov, S. G., and Anderson, G. B. (2008). Culture of porcine embryonic germ cells in serum-supplemented and serum-free conditions: the effects of serum and growth 
factors on primary and long-term culture. Cloning Stem Cells 10, 263-276. doi: 10.1089/clo.2007.0085.

Ryu, B., Kubota, H., Avarbock, M. R., and Brinster, R. L. (2005). Conservation of spermatogonial stem cell self-renewal signaling between mouse and rat. Proc. Natl. Acad. Sci. USA.102,14302-14307. doi: 10.1073/pnas.0506970102

Sahare, M., Otomo, A., Komatsu, K., Minami, N., Yamada, M., and Imai, H. (2014). The role of signaling pathways on proliferation and self-renewal of cultured bovine primitive germ cells. Reprod. Med. Biol. doi 10.1007/s12522-014-0189-x

Seandel, M., James, D., Shmelkov, S. V., Falciatori, I., Kim, J., Chavala, S., Scherr, D. S., Zhang, F., Torres, R., Gale, N.W., Yancopoulos, G. D., Murphy, A., Valenzuela, D. M., Hobbs, R. M., Pandolfi, P. P., and Rafii, S. (2007). Generation of functional multipotent adult stem cells from GPR125 1 germline progenitors. Nature 20, 346-50. doi:10.1038/nature06129

Struijk, R. B., Mulder C. L., van der Veen, F., van Pelt, A. M. M., and Repping, S. (2013). Restoring fertility in sterile childhood cancer survivors by autotransplanting spermatogonial stem cells: are we there yet?. Biomed. Res. Int. 2013, 903142. doi: 10.1155/2013/903142

Vergouwen, R. P., Hiskamp, R., Bas, R. J., Roepers-Gajadien, H. L., Davids, J. A., and de Rooij, D. G. (1993). Postnatal development of testicular cell populations in mice. J. Reprod. Fertil. 99, 479- 488. doi: 10.1530/jrf.0.0990479

Wu, Z., Falciatori, I., Molyneux, L. A., Richardson, T. E., Chapman, K. M., Hamra, F. K. (2009). Spermatogonial culture medium : an effective and efficient nutrient mixture for culturing rat spermatogonial stem cells. Biol. Reprod. 86, 77-86. doi: 10.1095/biolreprod.108.072645

Ying, Q. L., Nichols, J., Chambers, I., and Smith, A. (2003). BMP induction of Id protins suppresses differentiation and sustains embryonic stem cell self-renewal in collaboration with STAT3. Cell.115, 281-292. 


\section{Figure Legend}

Fig. 1. Effects of different extracellular matrix substrates for culture dish on the proliferation ratios of gonocytes in culture. A) Phase-contrast micrograph of freshly isolated and enriched gonocytes (white arrows) and somatic cells (green arrow). Bar $=20$ $\mu \mathrm{m}$. B) Assessment of gonocytes by germ cell marker UCHL1 (white arrow, left panel) and somatic cell marker VIMENTIN (VIM, green arrow, right panel). Bar=20 $\mu \mathrm{m}$. C) Appearance of colonies on different coating substrates at 7 days after the initiation of culture; a) gelatin, b) poly-L-lysine, c) collagen and d) DBA . D) Germ cell- to somatic cell ratios at the initiation of culture (day 0; D0) and at day 7 (D7) on dishes coated with different substrates; GLL (gelatin), PLL (poly-1-lysine), COL (collagen) and DBA. The germ cell- to somatic cell ratio was estimated by the germ cell-specific marker DBA $(\mathrm{n}=4)$. Data are presented as mean \pm SEM. $* * \mathrm{P}<0.05$ and $\mathrm{ns}$ (not significant) compared with the gonocytes /somatic cell ratio at day 0 . E) Cells were stained with DBA-FITC conjugate to identify gonocytes at day 7 of culture from dishes coated with different substrates; $a$ and a') GLL, b and b') PLL, c and c') COL and d and d') DBA. Bar $=50 \mu \mathrm{m}$.

Fig. 2. Proliferation of gonocytes in different culture conditions at different culture periods. The fold expansion of gonocytes at each passage was determined by counting the DBA-positive cells. Data are from three independent experiments using three different testes. Control (no supplement added to the medium). KSR, B27 and StemPro-SFM (the medium supplemented with the respective serum-free supplement). Data are presented as mean \pm SEM. $* \mathrm{P}<0.05$.

Fig. 3. Phenotypes of colonies in medium supplemented with KSR on poly-L-lysine-coated dishes at different passages. a) 7 days after initiation of culture, b) passage 5, c) passage 13 and d) passage 5 ( $40 \mathrm{X}$ magnification). Bar $=50 \mu \mathrm{m}$.

Fig. 4. Long-term culture of gonocytes in medium supplemented with KSR on poly-L-lysine-coated dishes. The total numbers of gonocytes at every passage were counted by germ cell marker DBA. The fold expansions of gonocytes were plotted. Data are from three independent experiments using three different testes. The number of cells increased by 144 fold over a 2 months period.

Fig. 5. RT-PCR analysis of gene expressions of cultured cells at different culture periods. Colonies were collected at the time of passages P0, P5, P10 and P13, respectively. M: 100bp DNA ladder, BT: Neonatal testis (10 days old), PT: Positive control (Genomic DNA). 
Fig. 6. Chromosomal analysis of cultured cells. A) Metaphase spread at passage 10 from representative cell lines, B) Representation of image (A) showing marked chromosome numbers from 1 to 60 . The images showed normal karyotype with 60 chromosomes. Bar $=20 \mu \mathrm{m}$.

Fig. 7. Characterization for germ cell colonies in culture. Colonies at passage 10 were double immunostained with DBA and specific marker proteins for stem cells (NANOG, E-CAD and OCT3/4) and germ cells (DDX4 and GFR $\alpha-1$ and proliferating cell marker (Ki67). Bar $=50 \mu \mathrm{m}$.

Fig. 8. Formation of embryoid body and differentiation potential of cultured gonocytes A) Phase-contrast image of embryoid body, B) Immunostaining with differentiation specific markers A-A') AFP and Hoechst, B-B') ASM and Hoechst, C-C') GFAP and Hoechst, D-D') Control and Hoechst. Control tissue section was prepared from teratoma tissue generated from mouse ES cell lines. The tissue section for positive control of AFP (E), ASM (F) and GFP (G) antibodies. The control section was incubated without primary antibody $(\mathrm{H})$. Bar $=50 \mu \mathrm{m}$. 
Figure 1

A

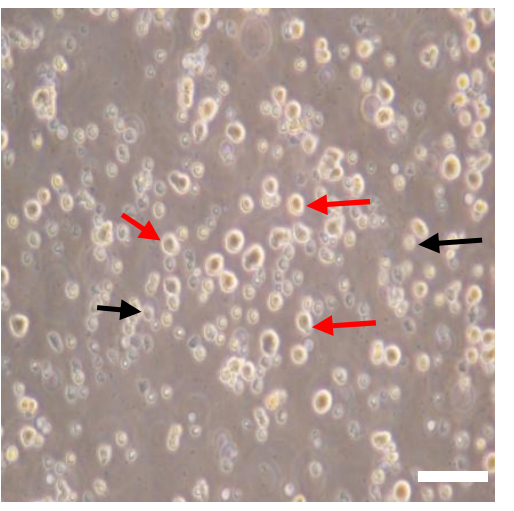

B
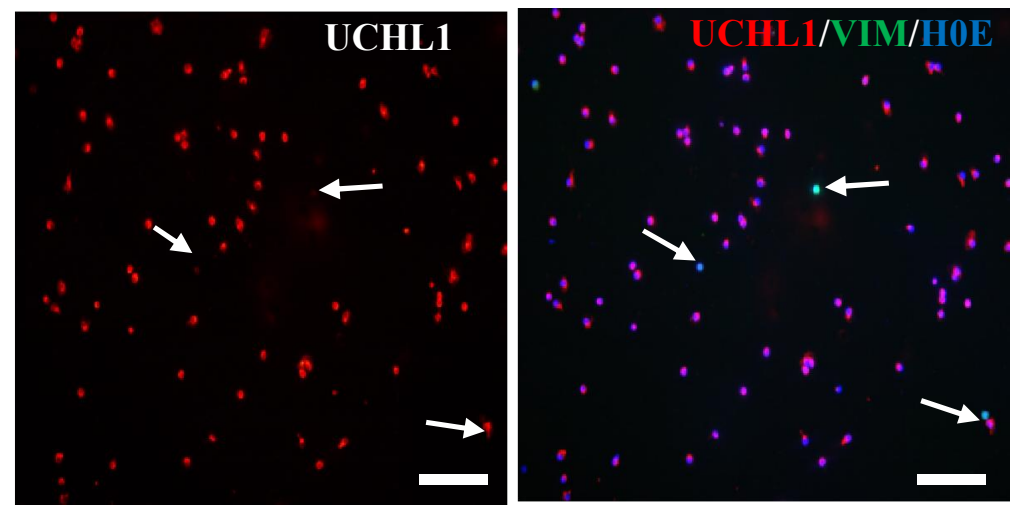

C
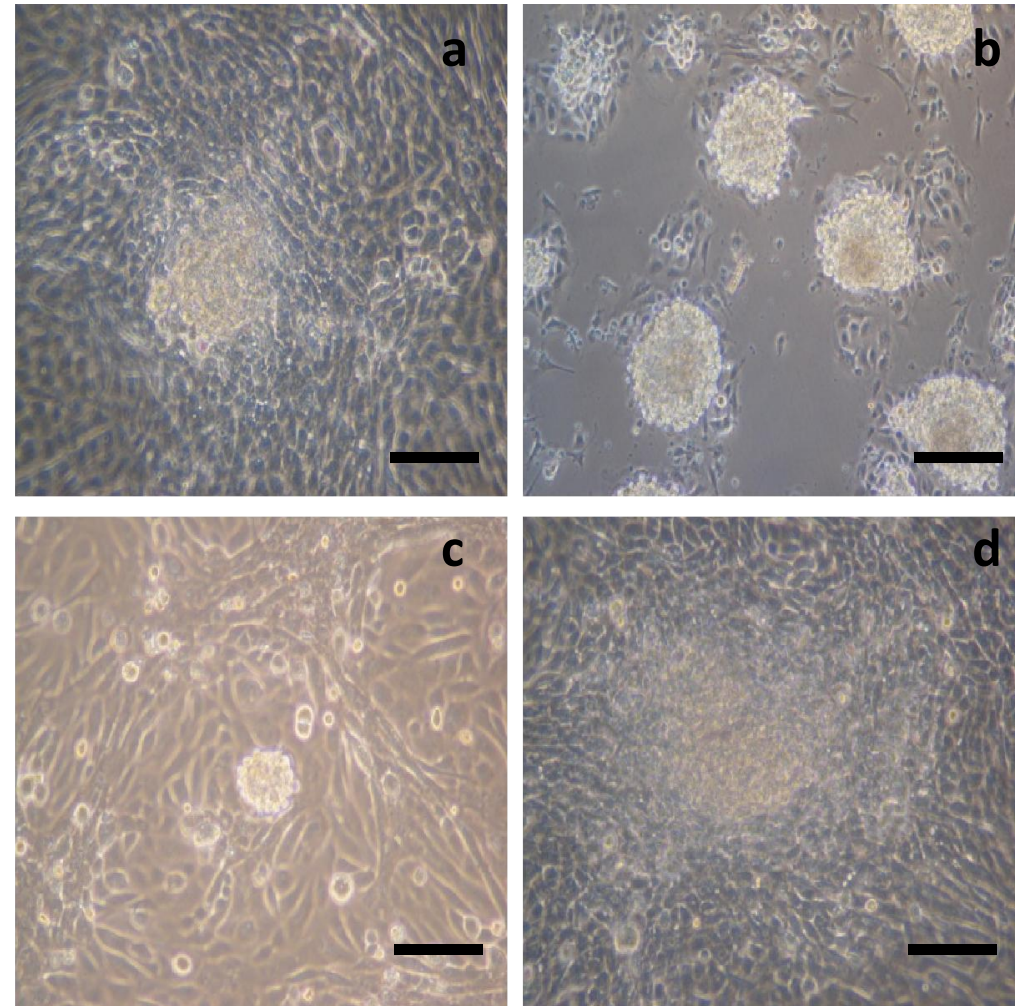
D

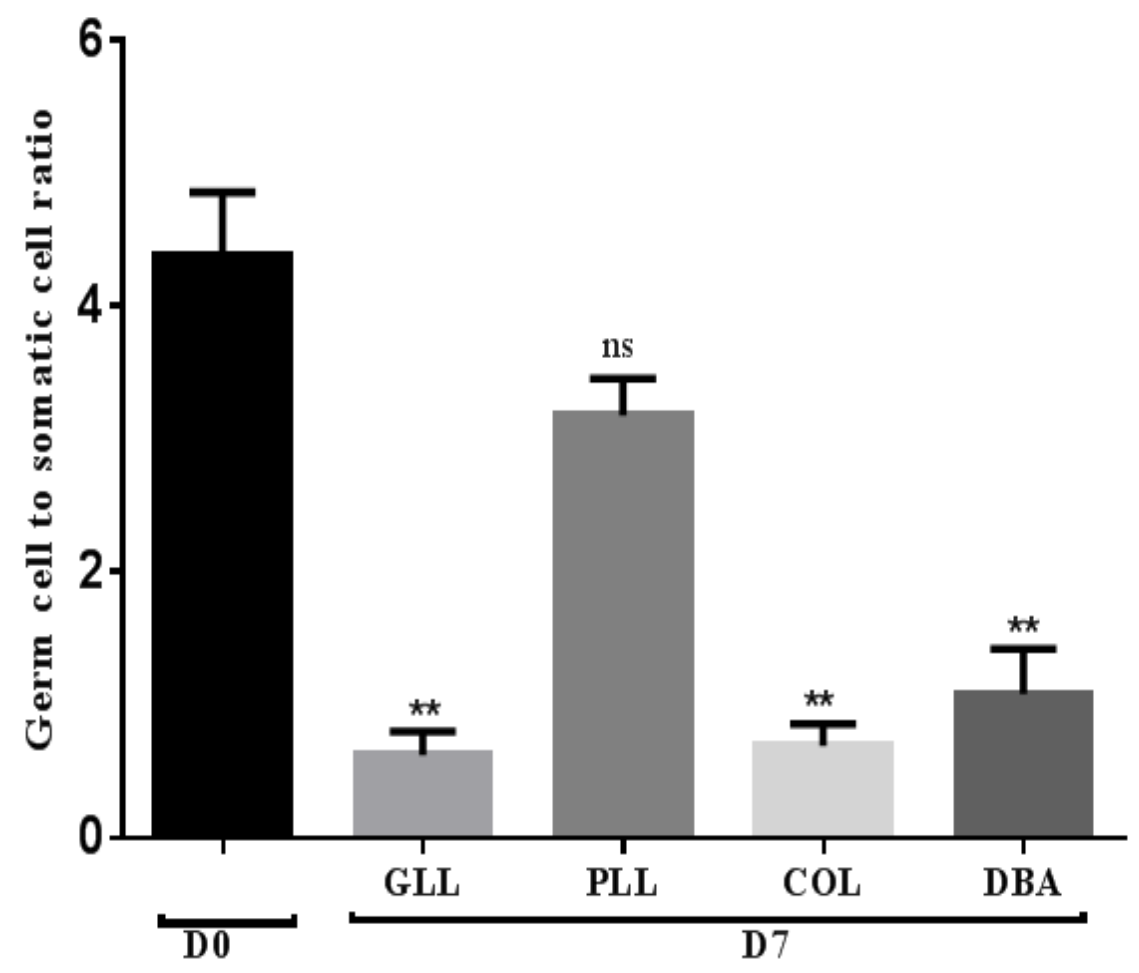

Primary culture on differ ent ECM 


$$
\text { ] }
$$


Figure 2

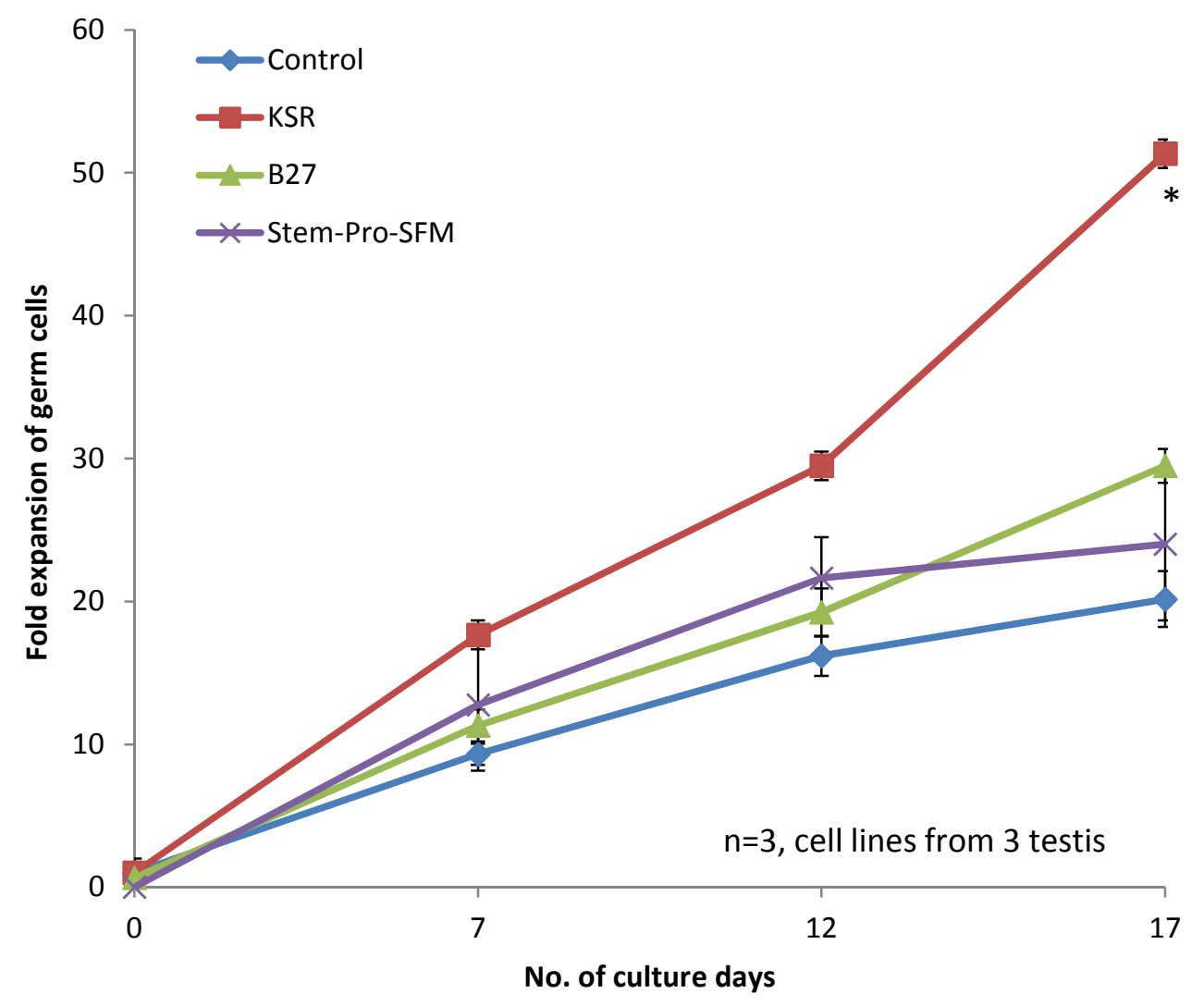


Figure 3
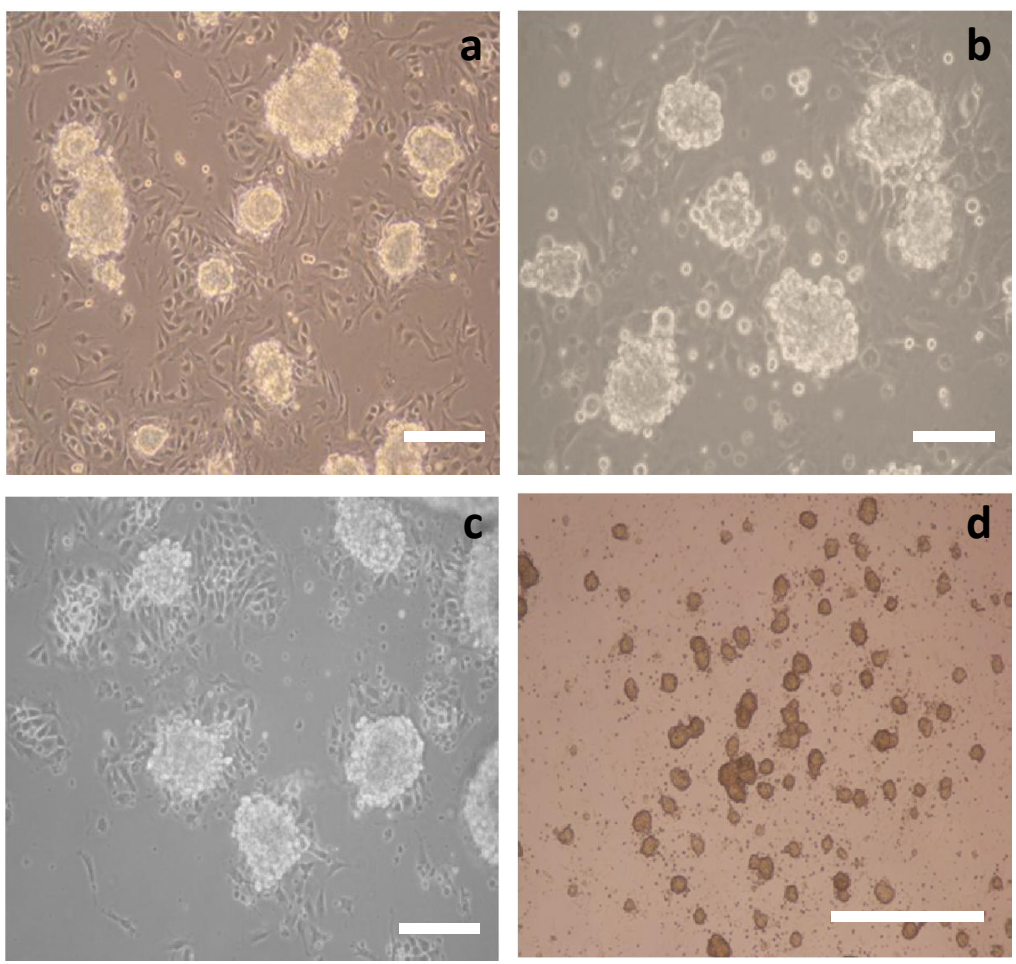
Figure 4

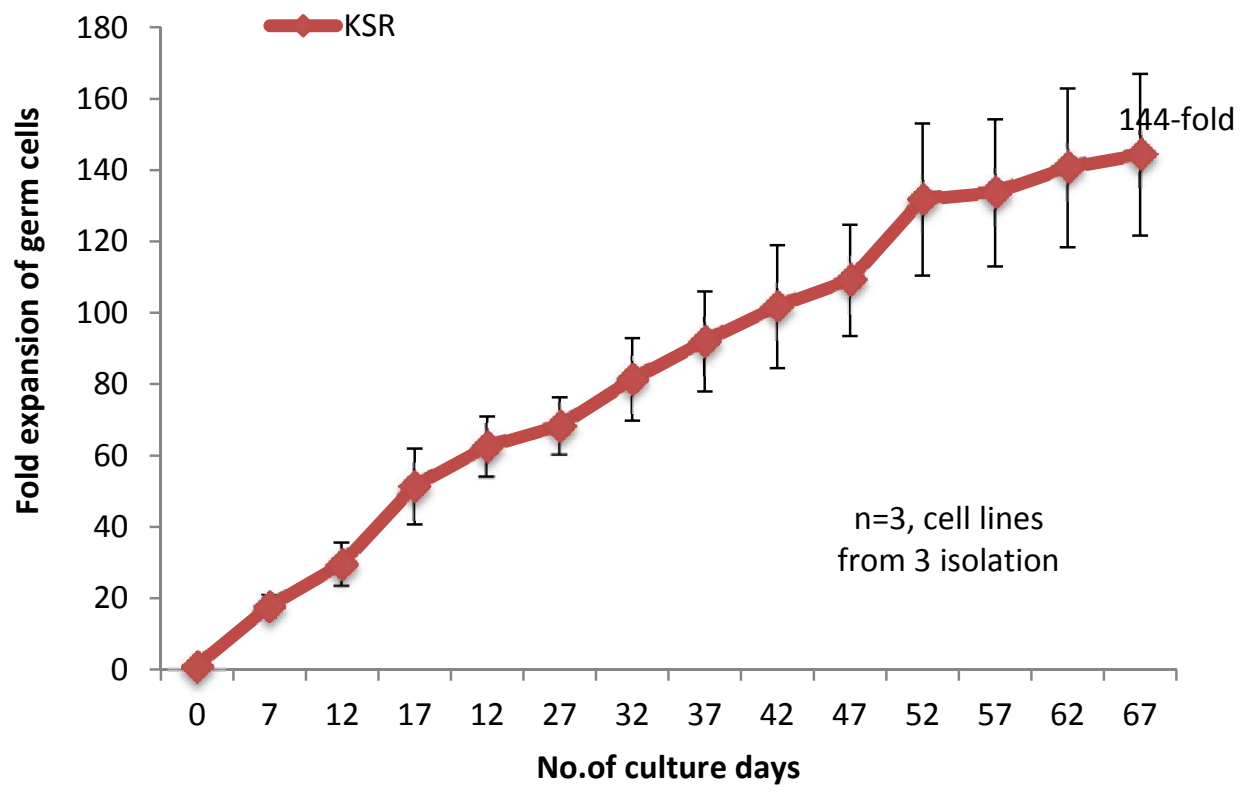


Figure 5

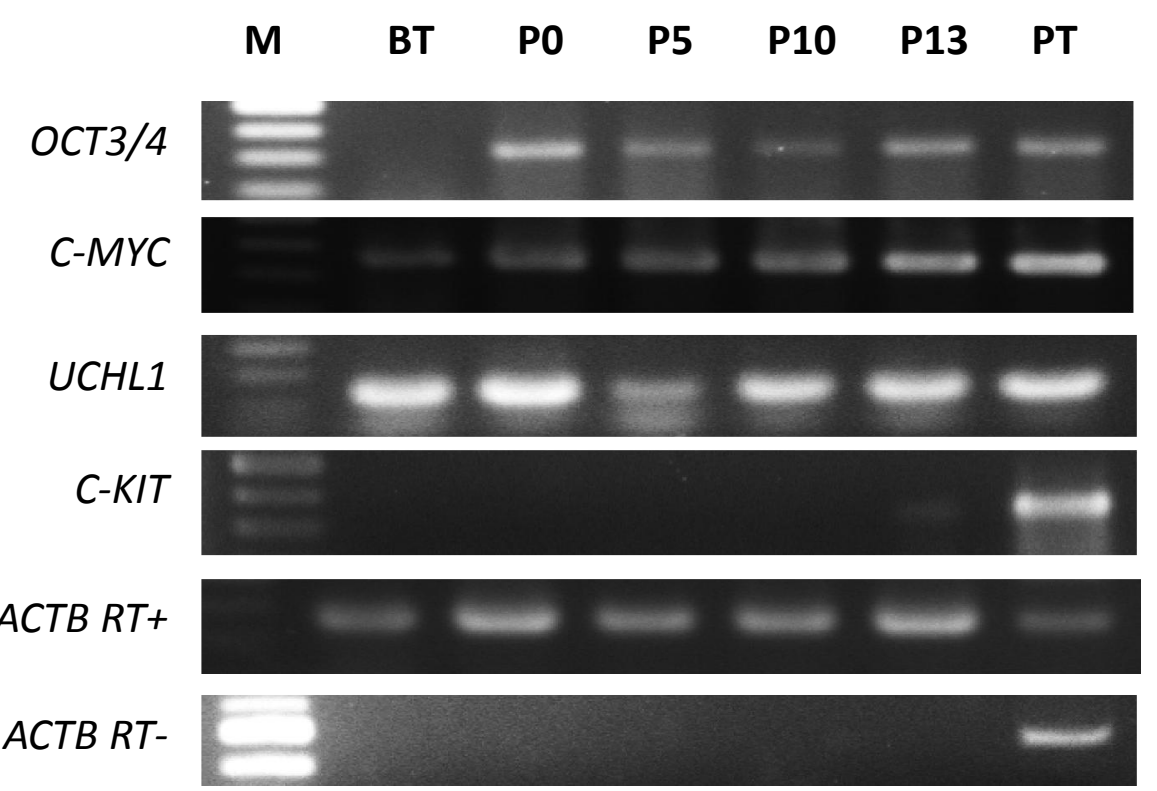


Figure 6
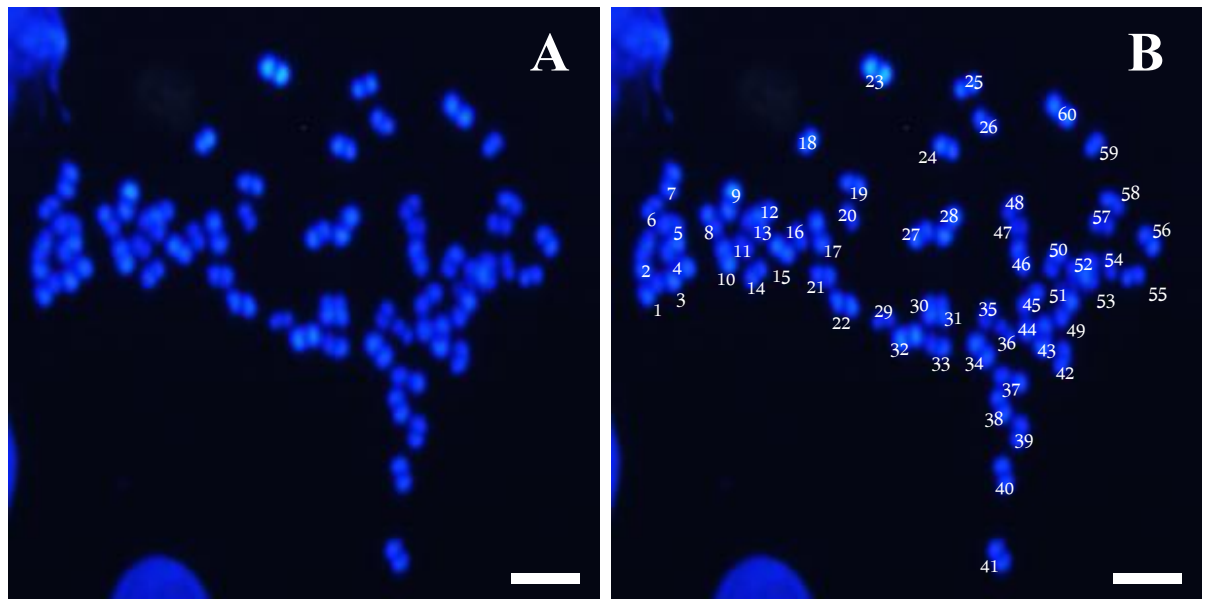
Figure 7
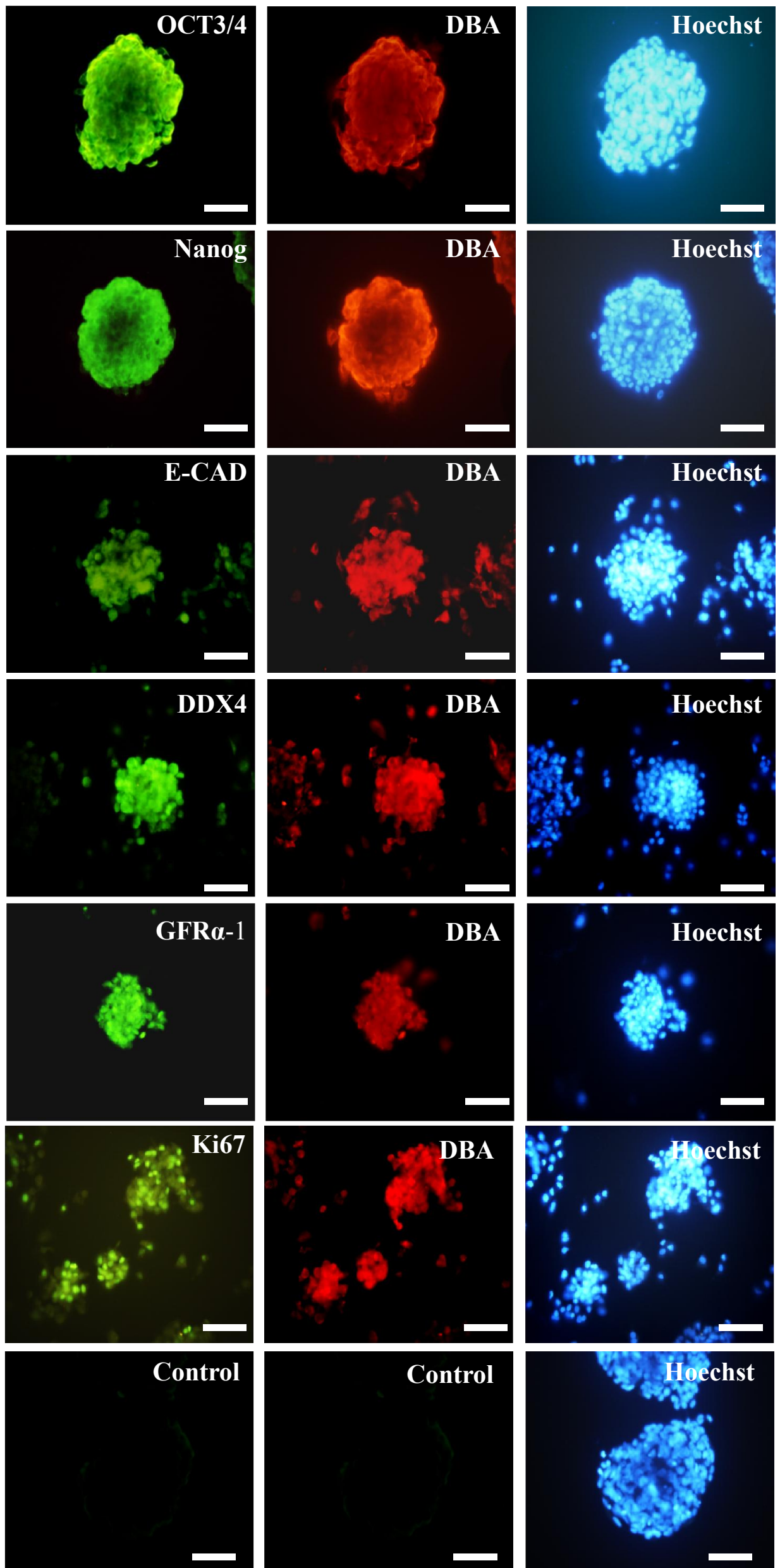
Figure 8

A

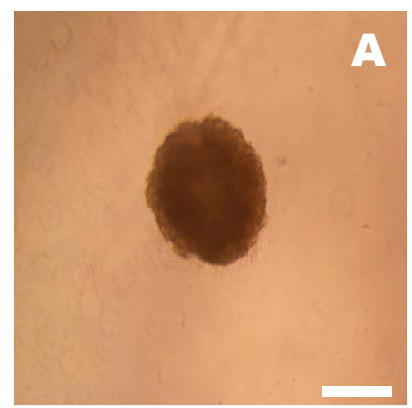

B
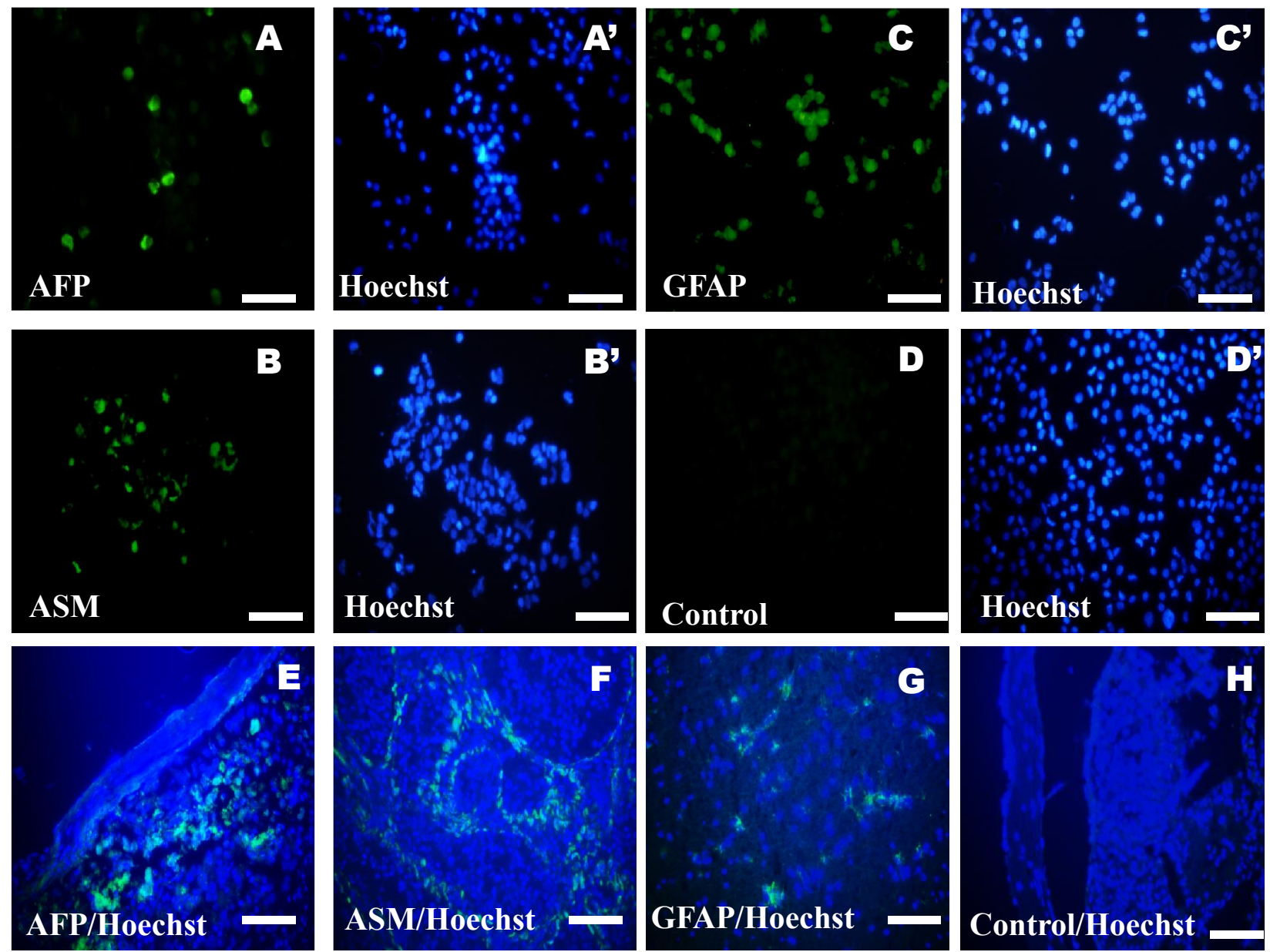

\section{H}

